\title{
Improved Prediction Model for Dynamic Resilient Modulus of Subgrade Silty Clay in Eastern Hunan and Its Relevant Finite Element Method Implementation
}

\author{
Dong Cheng ${ }^{1,2, *}$, Zheng Guo-yong ${ }^{2}$, Liu Wen-jie ${ }^{1,2}$, Zhou Lun ${ }^{1}$, Zhang Rui-lei ${ }^{1}$ \\ ${ }^{1}$ Hunan Communication Research Institute Limited Company, Changsha, China \\ ${ }^{2}$ School of Civil Engineering, Central South University, Changsha, China
}

Email address:

dongcheng4321@126.com (Dong Cheng),gyzhengwhx@163.com (Zheng Guo-yong), liuwje@163.com (Liu Wen-jie), 18769788330@163.com (Zhou Lun),1454370514@qq.com (Zhang Rui-lei)

${ }^{*}$ Corresponding author

To cite this article:

Dong Cheng, Zheng Guo-yong, Liu Wen-jie, Zhou Lun, Zhang Rui-lei. Improved Prediction Model for Dynamic Resilient Modulus of Subgrade Silty Clay in Eastern Hunan and Its Relevant Finite Element Method Implementation. American Journal of Civil Engineering. Vol. 6, No. 1, 2018, pp. 44-54. doi: 10.11648/j.ajce.20180601.18

Received: December 28, 2017; Accepted: January 19, 2018; Published: February 3, 2018

\begin{abstract}
With the enhancement of transportation speed and axle load, dynamic response of subgrade increases significantly. In order to improve the calculation accuracy of subgrade response under complex stress state, it is necessary to use dynamic indicators instead of static indicators in calculative process. For the sake of investigating the influence factor of dynamic resilient modulus of subgrade silty clay in Eastern Hunan, resilient modulus tests were carried out by conducting repeated load tri-axial tests. Based on available model, an improved resilient modulus prediction model considering four parameters was proposed by introducing k4. Corresponding accurate consistent tangent stiffness matrix was derived. Afterward, the improved model was implemented into finite element method software and verification work was put forward both on single element and pavement-subgrade structure. Finally, calculated results were compared with in-site measured results. Study achievements demonstrate that the improved model exhibits a higher precision and efficiency on single element because $\mathrm{k} 4$ can better adjust the affecting proportion of octahedral shear stress. When applied to analysis on pavement-subgrade structure, the improved model can reflect subgrade resilient modulus distribution and evolution more factually. In addition, numerical calculated result nearly coincides with measured results, which shows the application value of the improved model.
\end{abstract}

Keywords: Silty Clay, Dynamic Resilient Modulus, Prediction Model, Consistent Tangent Stiffness Matrix, Finite Element Method

\section{Introduction}

Currently, the design theory of subgrade and pavement structure is based on statics, analysis parameters are also used static parameters. It presumes that each structure layer is homogeneous material and presented by resilient modulus and Poisson's ratio. The stiffness parameter represented by modulus is independent of stress state applied to subgrade [1]. This structure analysis is reasonable under low-speed, low axle load traffic. However, the development of high speed and heavy traffic is the inevitable trend of China's transportation. With the increase of speed and axle load, the dynamic response of subgrade will increase significantly. Therefore, in order to acquire more accurate result of dynamic response, it is necessary to adopt dynamic resilient modulus in calculation and design on pavement-subgrade structure [2,3,4].

The dynamic resilient modulus is usually measured by imposing cylindrical specimens to repeated load Tri-axial tests $[5,6,7,8]$. Recent studies have established some prediction models of dynamic resilient module for quantitatively expressing the resilient behavior of soil. Therein, the most commonly used models are the so-called universal models that relate the modulus to the deviator stress (or octahedral shear stress), confining stress or a combination of them [9]. In current, representational universal models include UZANP1 model [10] and N37A model [11]. The latter was presented in 
highway roadbed design on the project NCHRP 1-37A in America and avoided the problem of the uncertain value of modulus and the dimension inconformity. Afterward, much improvement work based on N37A model was proposed [12, $13,14]$.

In view of the approaches differ in specimen size, compaction method, loading time, stress sequence and soil type, available models may not be completely suitable for exhibiting dynamic resilient behaviors of a particular soil. Some targeted modification and validity work need to be carried out. This article initially studied the resilient behavior through repeated load tri-axial tests (RLTT) on Eastern Hunan Silty Clay (EHSC). Based on N37A model, an improved prediction model (N37AP1) considering four parameters was proposed by introducing parameter $k_{4}$, whose advantage is proved by comparison with some available models. Next, the consistent tangent stiffness matrix of N37AP1 is derived and implemented into ABAQUS by compiling the user material subroutine (UMAT). Finally, finite element method (FEM) calculations embedded with N37AP1 model were carried out both on single element and pavement-subgrade structure. Corresponding verification work was put forward. The comparison between calculated results and in-site measured results was also analyzed to show the accuracy and application value of the improved model.

\section{Experiment}

\subsection{Material}

EHSC is a widely-used materials for filling subgrade in Eastern Hunan. Some property indexes of EHSC are shown in Table 1.

Table 1. Property indexes of EHSC.

\begin{tabular}{|c|c|c|c|c|c|}
\hline$\rho_{\mathrm{dmax}}{ }^{\mathrm{a}} /\left(\mathrm{g} \cdot \mathrm{cm}^{-3}\right)$ & $w_{\text {opt }}^{b} / \%$ & $w_{\mathrm{L}}^{\mathrm{c}} / \%$ & $w_{\mathrm{P}}^{\mathrm{d}} / \%$ & $D(d<2 \mathrm{~mm})^{\mathrm{e}} / \%$ & $D(d<0.074 \mathrm{~mm}) / \%$ \\
\hline 1.91 & 15.21 & 30.32 & 17.63 & 100 & 58.40 \\
\hline
\end{tabular}

${ }^{\mathrm{a}} \rho_{\mathrm{dmax}}=$ maximum dry density; ${ }^{\mathrm{b}} w_{\mathrm{opt}}=$ optimum water rate; ${ }^{\mathrm{c}} w_{\mathrm{L}}=$ liquid limit; ${ }^{\mathrm{d}} w_{\mathrm{P}}=$ plasticity; ${ }^{\mathrm{e}} D=$ mass percentage.

\subsection{Repeated Load Tri-Axial Tests (RLTT)}

RLTT is commonly used to establish the mechanical characteristics of soil and describe the resilient behaviour as well. The resilient modulus is defined as the ratio of the applied deviator stress and the resulting axial resilient (recoverable) strain [15].

The RLTT was carried out with GDSLAB cyclic tri-axial apparatus. The specimens for RLTT have a diameter of 100 $\mathrm{mm}$ and a height of $200 \mathrm{~mm}$. These specimens were compacted in a rigid mold with three levels of moisture content $w\left(w_{\mathrm{opt}}+3 \%, w_{\mathrm{opt}}, w_{\mathrm{opt}}-3 \%\right)$ and two levels of compaction degree $K(93 \%, 96 \%)$. Therein, refer to the Code for Design of Highway Subgrade of China, specimens with $K=96 \%$ represent roadbed layer and those with $K=93 \%$ represent embankment layer. The moisture content $w^{\prime}$ after repeated load was also measured. The relative error between $w$ and $w^{\prime}$ should not exceed $1 \%$. Effects of water content on specimens' structure and mechanical behavior in compaction process were assumed to be ignorable.

An initial confining pressure $\sigma_{3}(15 \mathrm{kPa}, 30 \mathrm{kPa}, 45 \mathrm{kPa}$, $60 \mathrm{kPa}$ ) was imposed on the specimens. Next cyclic deviator stress $\sigma_{\mathrm{d}}$ was imposed on the axial direction with stress-controlled sinusoidal loadings at $5 \mathrm{~Hz}$. Usually, the cyclic stress caused by vehicle loading in subgrade is less than $80 \mathrm{kPa}$. Nevertheless, the range of cyclic deviator stress is enlarged $(30 \mathrm{kPa}, 55 \mathrm{kPa}, 80 \mathrm{kPa}, 105 \mathrm{kPa})$ in these tests for acquiring variation trend of dynamic resilient modulus more conveniently. Each specimen was first subjected to 1000 applying loading cycles to stabilize the permanent deformations (at the end of this condition, the increase in the axial plastic deformation was lower than $10^{-7}$ per cycle). Afterward, a series of cyclic loads (100 cycles) was applied with designed stress levels. The axial resilient (recoverable) strain at last five cycles were used to calculate resilient modulus.

\subsection{Testing RESULTS}

Figure 1 summarizes the dynamic resilient module $\left(M_{\mathrm{r}}\right)$ in terms of different stress state and compaction degree when $w=$ $w_{\text {opt. }}$ According to Figure 1 (a) and Figure 1 (b), the $M_{\mathrm{r}}$ of EHSC decreases with the rise of cyclic deviator stress, and the decrease rate enhances gradually. Meanwhile, as shown in Figure 1 (c) and Figure 1 (d), the $M_{\mathrm{r}}$ increases with the rise of bulk stress, mainly changing in a linear tendency. In addition, the influence of compaction degree on $M_{\mathrm{r}}$ is obvious. For example, when confining pressure $\sigma_{3}$ is $60 \mathrm{kPa}$ and deviator stress $\sigma_{\mathrm{d}}$ is $30 \mathrm{kPa}, M_{\mathrm{r}}$ of the specimen with $K=96 \%$ increases nearly $13.3 \%$ compared to the one with $K=93 \%$.

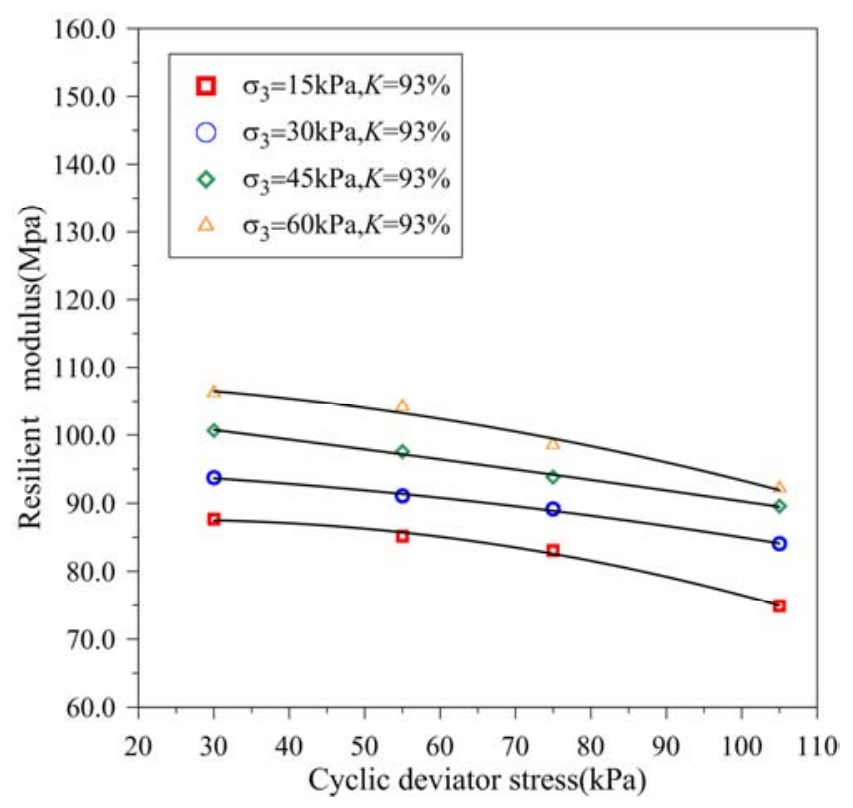

(a) 


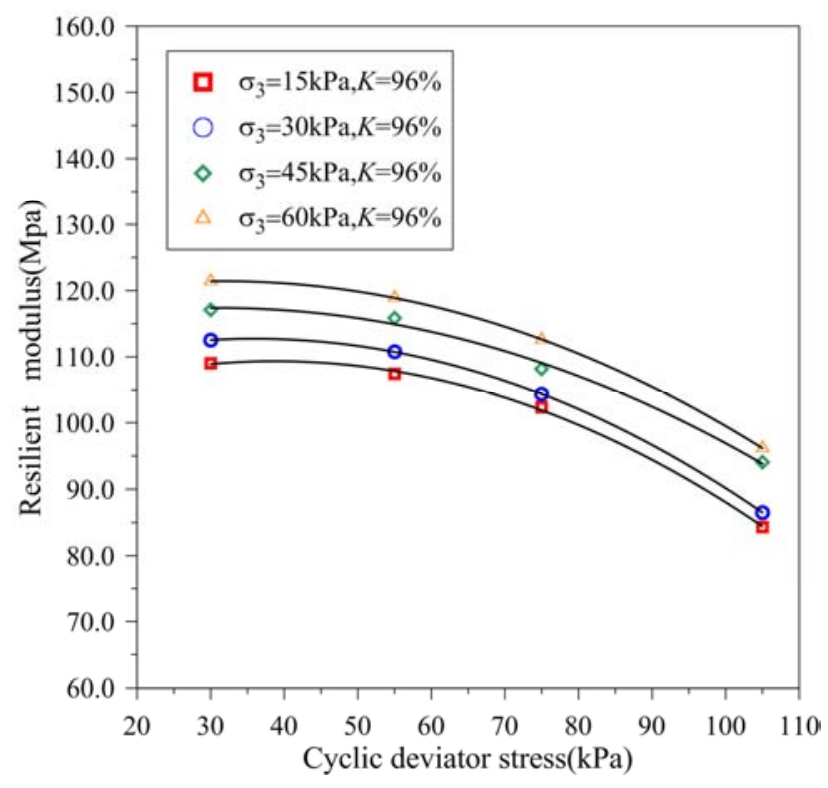

(b)

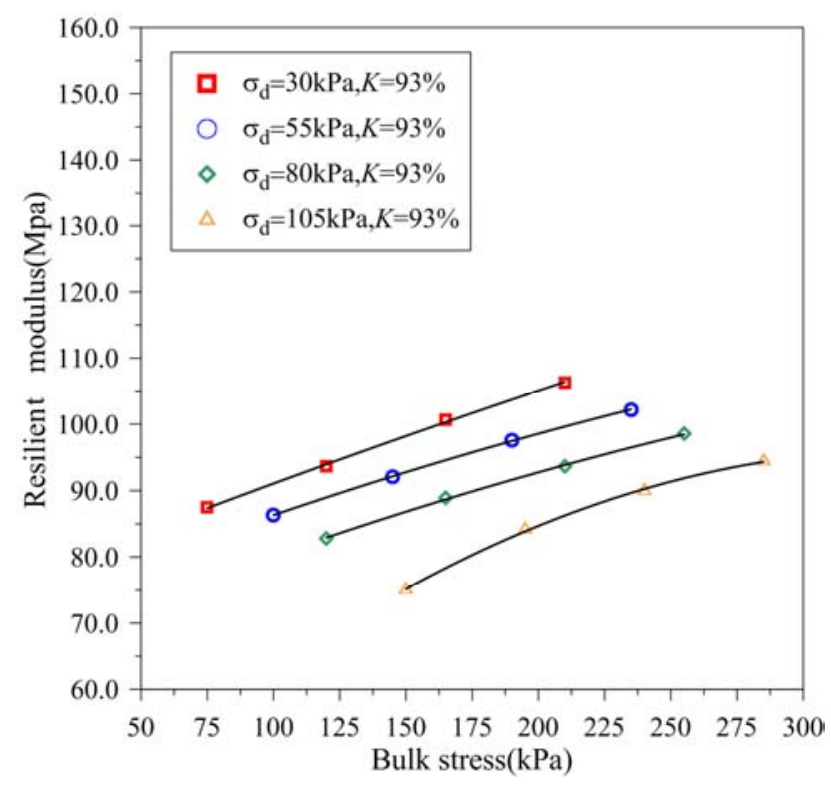

(c)

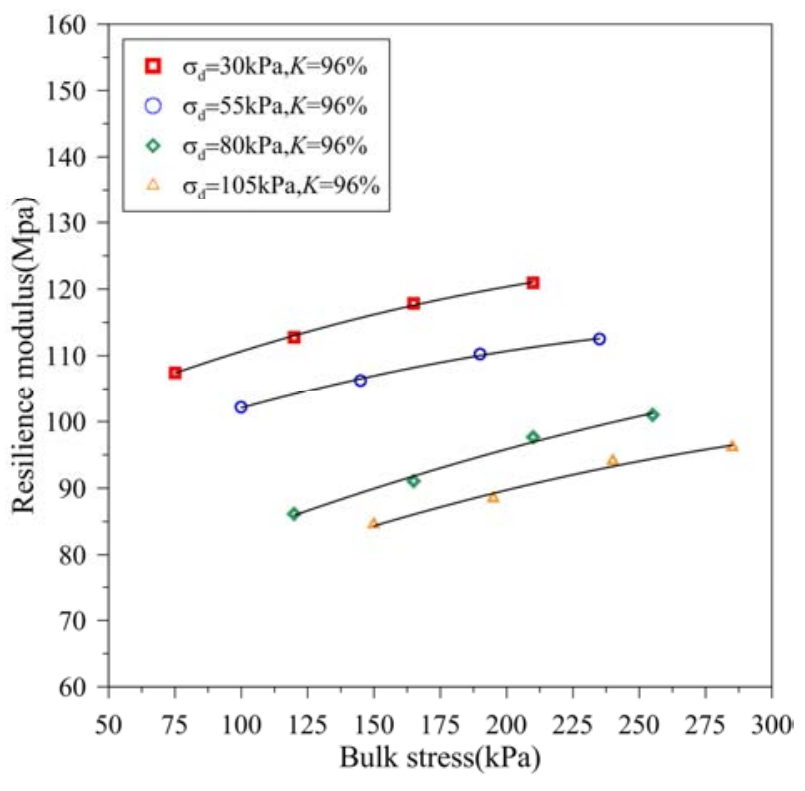

(d)

Figure 1. Relationship curve of $M_{r}$ and $\sigma_{d}, \theta$ with different compaction degree $\left(w=w_{\text {opt }}\right)$.

\section{Modelling Procedure and Evaluation}

\subsection{Modified Model Based on N37A and Related Regression Analysis}

The precondition of establishing a proper prediction model of dynamic resilient module is accurately setting up a relationship of stress and strain according to constitutive law, and the influence of other factors, such as compaction degree and moisture content, can be reflected by parameter in model expression. Note that for different subgrade soil, the impact of octahedral shear stress on $M_{\mathrm{r}}$ is significantly various $[16,17]$, another parameter $k_{4}$ is added into N37A model to fine adjust the affecting proportion of octahedral shear stress on $M_{\mathrm{r}}$. The improved model (abbreviated as N37AP1) with four model parameters is expressed as follows:

$$
M_{\mathrm{r}}=k_{1} P_{a}\left(\theta / P_{a}\right)^{k_{2}}\left(k_{4} \tau_{\mathrm{oct}} / P_{a}+1\right)^{k_{3}}
$$

Table 2. Regression results of prediction model $\left(k_{4}=0.1\right)$.

\begin{tabular}{|c|c|c|c|c|c|c|}
\hline Models & Compaction degree & Moisture content & $k_{1}$ & $k_{2}$ & $k_{3}$ & $D C^{2}$ \\
\hline \multirow{4}{*}{ N37AP1 } & \multirow{3}{*}{$96 \%$} & $w_{\mathrm{opt}}-3 \%$ & 1365.8 & 0.146 & -5.635 & 0.904 \\
\hline & & $w_{\mathrm{opt}}$ & 1302.2 & 0.136 & -9.010 & 0.881 \\
\hline & & $w_{\mathrm{opt}}+3 \%$ & 984.9 & 0.183 & -4.895 & 0.943 \\
\hline & $93 \%$ & $w_{\mathrm{opt}}$ & 1028.9 & 0.256 & -8.477 & 0.872 \\
\hline \multirow{3}{*}{ N37A } & \multirow{3}{*}{$96 \%$} & $w_{\mathrm{opt}}-3 \%$ & 1387.4 & 0.145 & -0.704 & 0.839 \\
\hline & & $w_{\mathrm{opt}}$ & 1335.0 & 0.134 & -1.124 & 0.813 \\
\hline & & $w_{\text {opt }}+3 \%$ & 1000.2 & 0.183 & -0.620 & 0.901 \\
\hline \multirow{4}{*}{ UZANP1 } & \multirow{3}{*}{$96 \%$} & $w_{\text {opt }}-3 \%$ & 971.3 & 0.137 & -0.137 & 0.719 \\
\hline & & $w_{\mathrm{opt}}$ & 756.9 & 0.12 & -0.218 & 0.679 \\
\hline & & $w_{\mathrm{opt}}+3 \%$ & 722.0 & 0.18 & -0.128 & 0.910 \\
\hline & $93 \%$ & $w_{\mathrm{opt}}$ & 606.0 & 0.247 & -0.217 & 0.744 \\
\hline
\end{tabular}

This model evolves to $K-\theta$ model [18-19] when $k_{4}$ takes a small value and it becomes N37A model when $k_{4}$ is 1 . For comparison, regression analysis results by using N37AP1 model, N37A model and UZANP1 model is shown in Table 2, 
where $k_{4}$ is fixed at 0.1 . Determination Coefficient (DC), which is based on resolving the square sum of total departure, is used to evaluate the fitting degree of regression. It is indicated that N37AP1 Model's fitting degree is the best because of largest DC value.

\subsection{Comparison of Prediction Results}

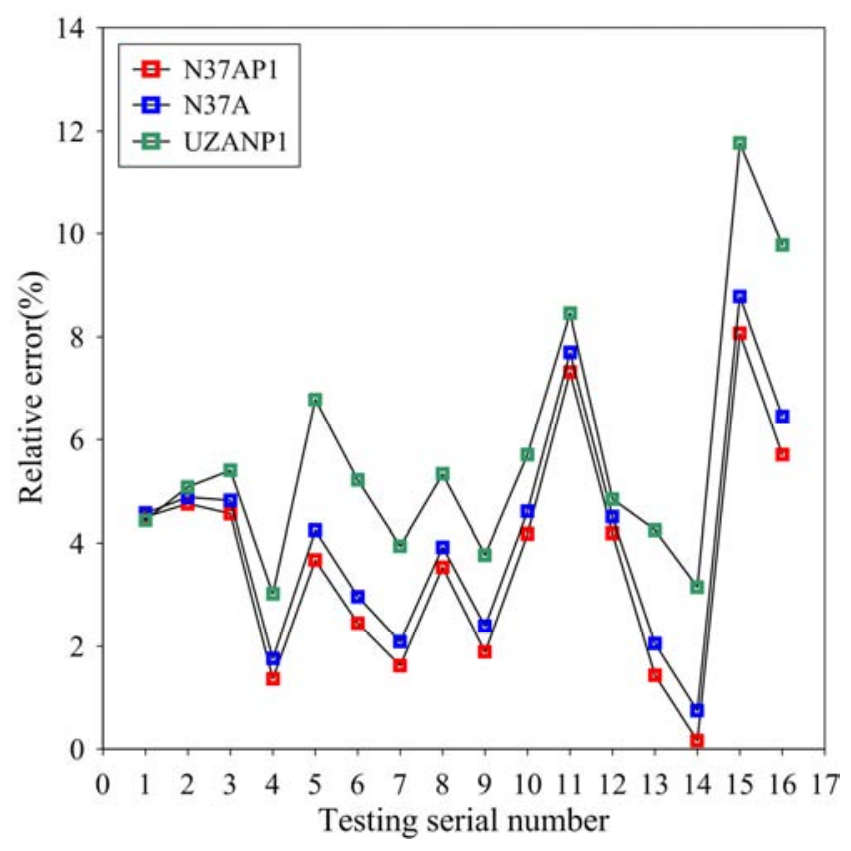

Figure 2. The relative errors of measured value.

In order to evaluate the prediction accuracy of N37AP1 model, based on measured value, relative prediction errors from different prediction models are given in Figure 2. It can be found that the errors of N37AP1 model $\left(k_{4}=0.1\right)$ are totally the smallest, generally retaining $70 \% \sim 90 \%$ of N37A Model and $50 \% \sim 70 \%$ of UZANP1 Model. Besides, the error of N37AP1 keeps less than 5\% when shear stress is small and increases slightly with rise of the shear stress. However, the maximum of relative error is $8.3 \%$, which indicates an ideal prediction accuracy.

\section{Derivation of Consistent Tangent Matrix of n37ap1model}

An important purpose of establishing a prediction model in this article is to implement N37AP1 model to FEM calculation based on ABAQUS, which can be realized by utilizing UMAT (user materials subroutine) interface. Because each analysis step of nonlinear solution in ABAQUS is proceeded by generating consistent tangent stiffness matrix, derivation of N37AP1 model's consistent tangent stiffness matrix in form of stresses becomes a significant precondition. The solution procedure is as follows:

The linear elastic constitutive relation can be expressed as:

$$
\boldsymbol{S}=E(\alpha \varepsilon \boldsymbol{I}+\boldsymbol{E}) /(1+v)
$$

where $E$ is strain tensor; $S$ is stress tensor; $E$ is modulus of linear elasticity; $\varepsilon=\operatorname{tr}(E)$ is bulk strain; $v$ is Poisson's ratio; $\alpha$ is defined as: $\alpha=v /(1-2 v)$. Similar to linear elastic constitution, by replacing $E$ with stiffness matrix $M_{\mathrm{r}}$ [20], the nonlinear elastic constitutive relation is derived as:

$$
\boldsymbol{S}=\boldsymbol{M}_{r}(\alpha \varepsilon \boldsymbol{I}+\boldsymbol{E}) /(1+v)
$$

where $I$ is unit matrix. Defining $C\left(\theta, \tau_{\text {oct }}\right)$ as:

$$
C\left(\theta, \tau_{\text {oct }}\right)=M_{\mathrm{r}}\left(\theta, \tau_{\text {oct }}\right) /(1+v)=k P_{a}\left(\theta / P_{a}\right)^{k_{2}}\left(k_{4} \tau_{\text {oct }} / P_{a}+1\right)^{k_{3}}
$$

where $k_{1}, k_{2}, k_{3}, k_{4}$ are parameters of N37AP1 model; $\theta$ is bulk stress (compression condition); $P_{a}$ is standard atmospheric pressure; $\tau_{\text {oct }}$ is octahedral shear stress; $k$ is defined as: $k=k_{1} /(1+v)$.

Substituting Equation (4) into Equation (3) gives:

$$
\boldsymbol{S}=C\left(\theta, \tau_{\text {oct }}\right)(\alpha \varepsilon \boldsymbol{I}+\boldsymbol{E})
$$

The expression of bulk stress is derived as Equation (6):

$$
\operatorname{tr}(\boldsymbol{S})=3 C\left(\theta, \tau_{\text {oct }}\right) \alpha \varepsilon+C\left(\theta, \tau_{\text {oct }}\right) \varepsilon=C\left(\theta, \tau_{\text {oct }}\right) \varepsilon(3 \alpha+1) \sqrt{2}
$$

Bulk stress $\sigma$ and deviator stress tensor $\overline{\boldsymbol{S}}$ can then be converted as:

$$
\begin{gathered}
\sigma=\operatorname{tr}(\boldsymbol{S})=\bar{\alpha} C\left(\theta, \tau_{\text {oct }}\right) \varepsilon \\
\overline{\boldsymbol{S}}=C\left(\theta, \tau_{\text {oct }}\right) \overline{\boldsymbol{E}}
\end{gathered}
$$

where, $\bar{E}$ is deviator strain tensor; $\bar{\alpha}=3 \alpha+1=(1+v) /(1-2 v)$.

Defining $\zeta$ and $\gamma^{2}$ as:

$$
\zeta=|\varepsilon|
$$

$$
\gamma^{2}=1 / 3(\overline{\boldsymbol{E}}: \overline{\boldsymbol{E}})
$$

Equation (7) and Equation (8) can be converted as:

$$
\left\{\begin{array}{l}
\theta=\bar{\alpha} C\left(\theta, \tau_{\text {oct }}\right) \zeta \\
\tau_{\text {oct }}=C\left(\theta, \tau_{\text {oct }}\right) \gamma
\end{array}\right.
$$

Integrate Equation (4) into the equation above, Equation (11) becomes: 


$$
\left\{\begin{array}{l}
\theta=\bar{\alpha} k P_{a}\left(\theta / P_{a}\right)^{k_{2}}\left(k_{4} \tau_{\text {oct }} / P_{a}+1\right)^{k_{3}} \zeta \\
\tau_{\text {oct }}=k P_{a}\left(\theta / P_{a}\right)^{k_{2}}\left(k_{4} \tau_{\text {oct }} / P_{a}+1\right)^{k_{3}} \gamma
\end{array}\right.
$$

Equation (12) can be simplified as:

$$
\left\{\begin{array}{l}
\theta=\theta(\zeta, \gamma) \\
\tau_{\text {oct }}=\tau_{\text {oct }}(\zeta, \gamma)
\end{array}\right.
$$

Therefore, $C\left(\theta, \tau_{\text {oct }}\right)$ can be transformed as $C=C(\zeta, \gamma)$ and Equation (5) becomes:

$$
\boldsymbol{S}=C(\zeta, \gamma)(\alpha \varepsilon \boldsymbol{I}+\boldsymbol{E})
$$

The consistent tangent stiffness matrix of prediction model can then be expressed as:

$$
\frac{\partial \boldsymbol{S}}{\partial \boldsymbol{E}}=\mathrm{C}(\boldsymbol{\Gamma}+\alpha \boldsymbol{I} \otimes \boldsymbol{I})+(\alpha \varepsilon \boldsymbol{I}+\boldsymbol{E}) \otimes \nabla_{\boldsymbol{E}} \mathrm{C}
$$

where $\quad \boldsymbol{I}=\partial \mathcal{E} / \partial \boldsymbol{E} \quad$ or $\quad[\boldsymbol{I}]_{i j}=\delta_{i j} \quad ; \quad \boldsymbol{\Gamma}=\partial \boldsymbol{E} / \partial \boldsymbol{E} \quad$ or $[\Gamma]_{i j k l}=\left(\delta_{i k} \delta_{j l}+\delta_{j k} \delta_{i l}\right) / 2$.

Therein,

$$
\begin{aligned}
\nabla_{\boldsymbol{E}} \mathrm{C}(\boldsymbol{E})= & (\partial \mathrm{C} / \partial \theta)(\partial \theta / \partial \zeta)(\partial \zeta / \partial \boldsymbol{E})+\left(\partial \mathrm{C} / \partial \tau_{\text {oct }}\right)\left(\partial \tau_{\text {oct }} / \partial \zeta\right)(\partial \zeta / \partial \boldsymbol{E}) \\
& +(\partial \mathrm{C} / \partial \theta)(\partial \theta / \partial \gamma)(\partial \gamma / \partial \boldsymbol{E})+\left(\partial \mathrm{C} / \partial \tau_{\text {oct }}\right)\left(\partial \tau_{\text {oct }} / \partial \gamma\right)(\partial \gamma / \partial \boldsymbol{E})
\end{aligned}
$$

According to Equation (9) and Equation (10), Equation (17) and Equation (18) are derived as:

$$
\begin{gathered}
\partial \zeta / \partial \boldsymbol{E}=(\partial \zeta / \partial \varepsilon)(\partial \varepsilon / \partial \boldsymbol{E})=\operatorname{sgn}(\varepsilon) \boldsymbol{I} \\
\gamma^{2}=(\boldsymbol{E}-\boldsymbol{\varepsilon} \boldsymbol{I} / 3):(\boldsymbol{E}-\varepsilon \boldsymbol{I} / 3) / 3=\left[\boldsymbol{E}: \boldsymbol{E}-2 \varepsilon(\boldsymbol{I}: \boldsymbol{E}) / 3+\varepsilon^{2}(\boldsymbol{I}: \boldsymbol{I}) / 9\right] / 3 \\
=\left[\boldsymbol{E}: \boldsymbol{E}-2 \varepsilon^{2} / 3+\varepsilon^{2} / 3\right] / 3=\left[\boldsymbol{E}: \boldsymbol{E}-\varepsilon^{2} / 3\right] / 3
\end{gathered}
$$

Equation (19)-Equation (21) can then be acquired by differential of both sides of Equation (18):

$$
\begin{gathered}
2 \gamma \mathrm{d} \gamma=[2 \boldsymbol{E}: \mathrm{d} \boldsymbol{E}-(2 / 3) \varepsilon \mathrm{d} \varepsilon] / 3 \\
\gamma \mathrm{d} \gamma=[\overline{\boldsymbol{E}}: \mathrm{d} \boldsymbol{E}] / 3 \\
\partial \gamma / \partial \boldsymbol{E}=\overline{\boldsymbol{E}} /(3 \gamma)
\end{gathered}
$$

According to Equation (12), the following equations are acquired:

$$
\left\{\begin{array}{l}
\partial \theta / \partial \gamma=m k_{3} \theta C \\
\partial \theta / \partial \zeta=m \bar{\alpha} C\left(-k_{3} \tau_{\text {oct }}+\tau_{\text {oct }}+P_{a} / k_{4}\right) \\
\partial \tau_{\text {oct }} / \partial \gamma=m C\left(\tau_{\text {oct }}+P_{a} / k_{4}\right)\left(1-k_{2}\right) \\
\partial \tau_{\text {oct }} / \partial \zeta=m k_{2} \tau_{\text {oct }} \bar{\alpha} C\left(\tau_{\text {oct }}+P_{a} / k_{4}\right) / \theta
\end{array}\right.
$$

where $m=1 /\left(-k_{3} \tau_{\text {oct }}+\tau_{\text {oct }}+P_{a} / k_{4}-k_{2} \tau_{\text {oct }}-k_{2} P_{a} / k_{4}\right)$.

Integrating Equation (18), Equation (21), Equation (22)

$$
\boldsymbol{L}=\bar{\alpha} k_{2}\left(\tau_{\text {oct }}+P_{a} / k_{4}\right) \boldsymbol{I} \otimes \boldsymbol{I} / 3+\bar{\alpha} k_{2}\left(\tau_{\text {oct }}+P_{a} / k_{4}\right) \overline{\boldsymbol{S}} \otimes \boldsymbol{I} / \theta+\theta k_{3} \boldsymbol{I} \otimes \overline{\boldsymbol{S}} / 9 \tau_{\mathrm{oct}}+k_{3} \overline{\boldsymbol{S}} \otimes \overline{\boldsymbol{S}} / 3 \tau_{\mathrm{oct}}
$$

For programming convenience, the consistent tangent stiffness matrix can be simplified as:

$$
\partial \boldsymbol{S} / \partial \boldsymbol{E}=C\left(\boldsymbol{\Gamma}+d_{1} \boldsymbol{I} \otimes \boldsymbol{I}+d_{2} \overline{\boldsymbol{S}} \otimes \boldsymbol{I}+d_{3} \boldsymbol{I} \otimes \overline{\boldsymbol{S}}+d_{4} \overline{\boldsymbol{S}} \otimes \overline{\boldsymbol{S}}\right)
$$

where $d_{1}=\alpha+m \bar{\alpha} k_{2}\left(\tau_{\text {oct }}+P_{a} / k_{4}\right) / 3 ; d_{2}=m \bar{\alpha} k_{2}\left(\tau_{\text {oct }}+P_{a} / k_{4}\right) / \theta$; $d_{3}=m \theta k_{3} / 9 \tau_{\text {oct }} ; d_{4}=k_{3} / 3 \tau_{\text {oct }}$.

It can be found from Equation (25) that consistent tangent stiffness matrix is finally exhibited in terms of $\theta$ and $\tau_{\text {oct }}$, which are independent variable and can be calculated by stress into Equation (16) and assuming that $\varepsilon$ has the same sign with $\sigma$ gives:

$$
\begin{aligned}
\nabla_{\boldsymbol{E}} \mathrm{C} & =m\left[\begin{array}{l}
\bar{\alpha} k_{2} \mathrm{C}^{2}\left(-k_{3} \tau_{\mathrm{oct}}+\tau_{\mathrm{oct}}+P_{a} / k_{4}\right) \operatorname{sgn}(\varepsilon) \boldsymbol{I} / \theta \\
+\bar{\alpha} k_{2} k_{3} \tau_{\text {oct }} C^{2} \operatorname{sgn}(\varepsilon) \boldsymbol{I} / \theta \\
+k_{2} k_{3} \mathrm{C}^{2} \overline{\boldsymbol{E}} / 3 \gamma+k_{3} C^{2}\left(1-k_{2}\right) \overline{\boldsymbol{E}} / 3 \gamma
\end{array}\right] \\
& =m\left(\bar{\alpha} k_{2} \mathrm{C}^{2}\left(\tau_{\text {oct }}+P_{a} / k_{4}\right) \boldsymbol{I} / \theta+k_{3} C^{2} \overline{\boldsymbol{E}} / 3 \gamma\right)
\end{aligned}
$$

Substituting Equation (23) into Equation (15), the consistent tangent stiffness matrix can be expressed as a function of deviator stress:

$$
\begin{gathered}
\partial \boldsymbol{S} / \partial \boldsymbol{E}=C(\boldsymbol{\Gamma}+\alpha \boldsymbol{I} \otimes \boldsymbol{I})+(1 / 3 \bar{\alpha} \varepsilon \boldsymbol{I}+\overline{\boldsymbol{E}}) \otimes \nabla_{\boldsymbol{E}} C \\
=C(\boldsymbol{\Gamma}+\alpha \boldsymbol{I} \otimes \boldsymbol{I}+m \boldsymbol{L})
\end{gathered}
$$

where

tensor in analysis step. Afterward, stress increment can be calculated from strain increment and consistent tangent stiffness matrix. Stress tensor will be renewed and imported to the next analysis step. N37AP1 model will be recognized as material property in that progressive form until all the steps are finished. These procedures above were programed by Fortran language and compiled into ABAQUS through UMAT interface. 


\section{Verification Work}

\subsection{Verification on Single Element}

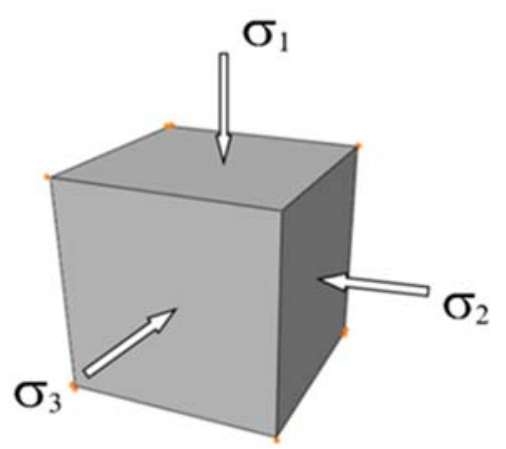

Figure 3. Schematic diagram of load and boundary condition on single element.

In order to verify the validity of the derived consistent tangent stiffness matrix and programming, a verification work was firstly carried out on single element C3D8 (8-node linear brick, see Figure 3 ) in ABAQUS, and $k_{4}$ was assigned with different values. The adopted N37AP1 model parameters are presented in Table 3.

Table 3. Parameter of N37AP1 model.

\begin{tabular}{lllll}
\hline Poisson's ratio $\boldsymbol{\mu}$ & $\boldsymbol{k}_{\mathbf{1}}$ & $\boldsymbol{k}_{\mathbf{2}}$ & $\boldsymbol{k}_{\mathbf{3}}$ & $\boldsymbol{k}_{\mathbf{4}}$ \\
\hline 0.25 & 400 & 0.3 & -0.2 & 1 \\
0.25 & 400 & 0.3 & -0.2 & 0.1 \\
0.25 & 400 & 0.3 & -0.2 & 10 \\
\hline
\end{tabular}

For single element, three adjacent surfaces' normal displacement is restrained and other three surfaces are imposed with normal loading. Initial loading values are: axial stress $\sigma_{1}=0 \mathrm{kPa}$, lateral stress $\sigma_{2}=\sigma_{3}=0 \mathrm{kPa}$; Final loading values are: $\sigma_{1}=100 \mathrm{kPa}$, lateral stress $\sigma_{2}=\sigma_{3}=10 \mathrm{kPa}$. Both of axial stress and lateral stress increase linearly.

The comparison of FEM calculation results and analytic solution (AS) are shown in Figure 4 Figure 5. For example, analytic solution of strain $\varepsilon_{1}$ can be expressed as:

$$
\varepsilon_{1}=\left[\sigma_{1}-v\left(\sigma_{2}+\sigma_{3}\right)\right] / M_{\mathrm{r}}
$$

where $M_{\mathrm{r}}$ can be calculated by Equation (1) when the values of $\sigma_{1}, \sigma_{2}, \sigma_{3}$ are known.

It can be inferred from Figure 4 and Figure 5 that FEM results are close to AS when $k_{4}$ is assigned with different values. Meanwhile, when $k_{4}$ is comparatively large, N37AP1 model approaches UZANP1 model. FEM results of strain become higher and the shear softening effect of specimens become more obvious. Otherwise, N37AP1 model approaches $K-\theta$ model. FEM results of strain become lower. Generally, $k_{4}$ reflects shear stress's influence degree.

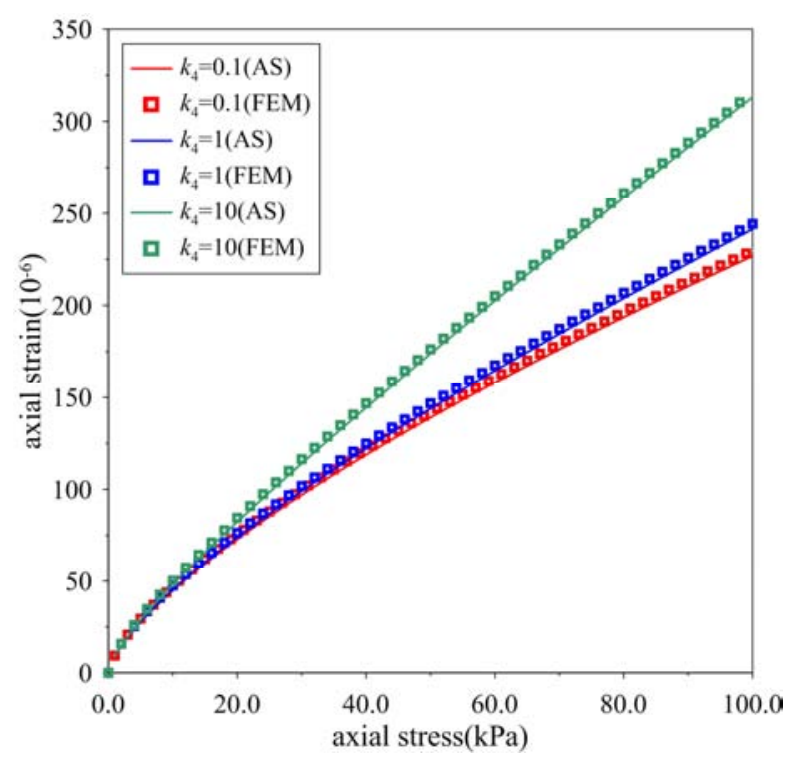

Figure 4. Relationship curve of $\varepsilon_{l} \sim \sigma_{l}$.

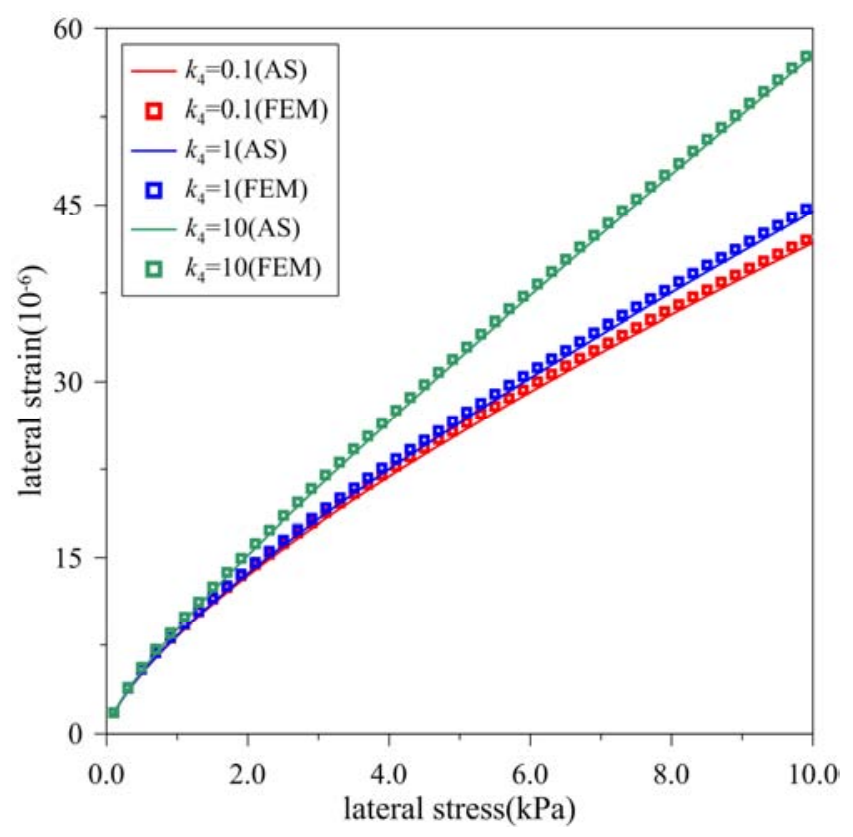

Figure 5. Relationship curve of $\varepsilon_{3} \sim \sigma_{3}$.

\subsection{Verification on Pavement-Subgrade Structure}

For further validity, N37AP1 model was implanted into numerical study with a three dimensional model to reflect the spatial distribution of dynamic responses. Only $1 / 4$ of the model were modeled due to symmetric conditions. Figure 6 shows the finite element mesh of the whole model, including pavement, subgrade and foundation. Hypothesizes are as follows: (1) pavement and foundation is homogeneous and isotropic linear elastic; (2) each structural layer is completely continuous at vertical direction. The material parameters were listed in Table 4. Input parameters of pavement and foundation are acquired from designing information of expressway structure. N37AP1 model parameters of subgrade adopt the value in Table 2 when $w=w_{\text {opt }}$. 
Table 4. Parameters of FEM model.

\begin{tabular}{llll}
\hline Name of the material & Thickness/cm & Resilient modulus/MPa & Poisson's ratio \\
\hline SMA & 4 & 1800 & 0.15 \\
AC-20 & 6 & 1600 & 0.15 \\
AC-25 & 8 & 1500 & 0.15 \\
Cement stabilizing layer & 60 & 1000 & 0.20 \\
Roadbed $(K=0.96)$ & 80 & In Tab.2 & 0.35 \\
Embankment $(K=0.93)$ & 650 & In Tab.2 & 0.35 \\
Foundation & 800 & 40 & 0.38 \\
\hline
\end{tabular}

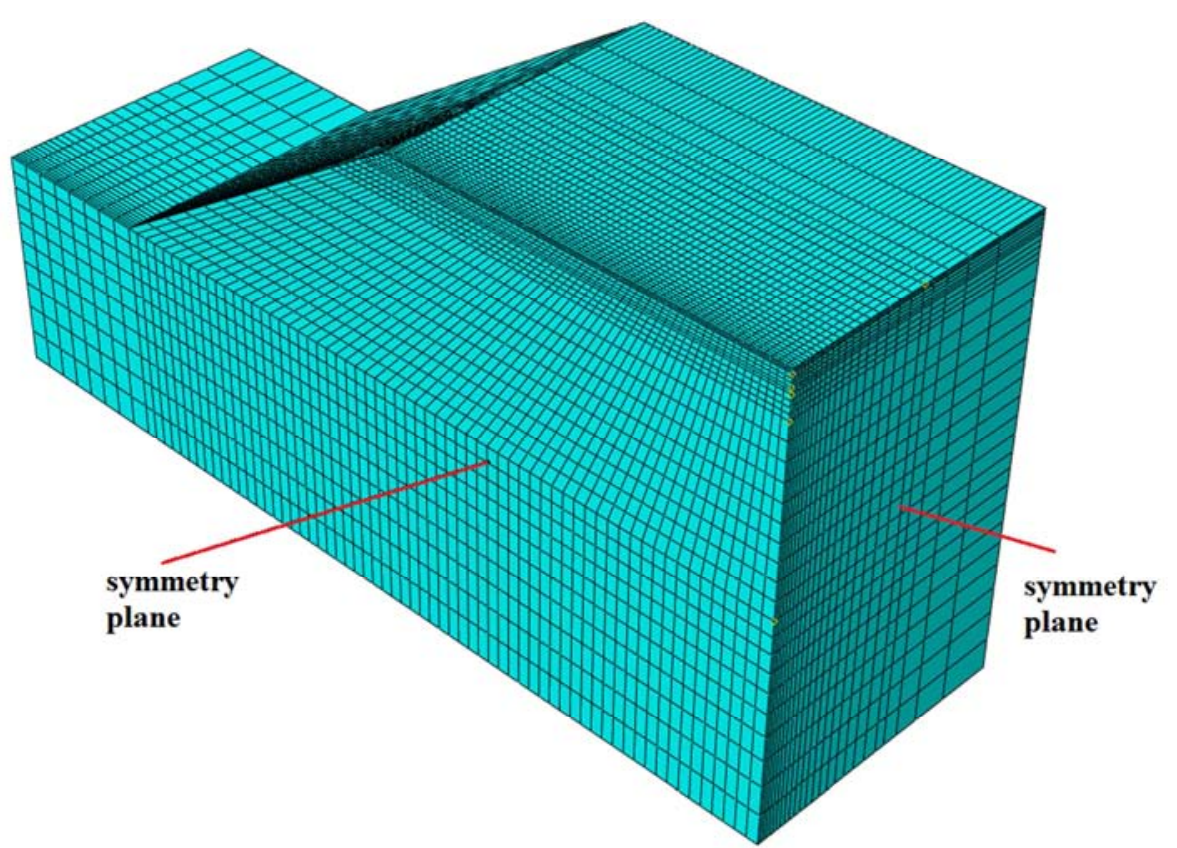

Figure 6. Geometry and mesh of the FEM model used for validity work.

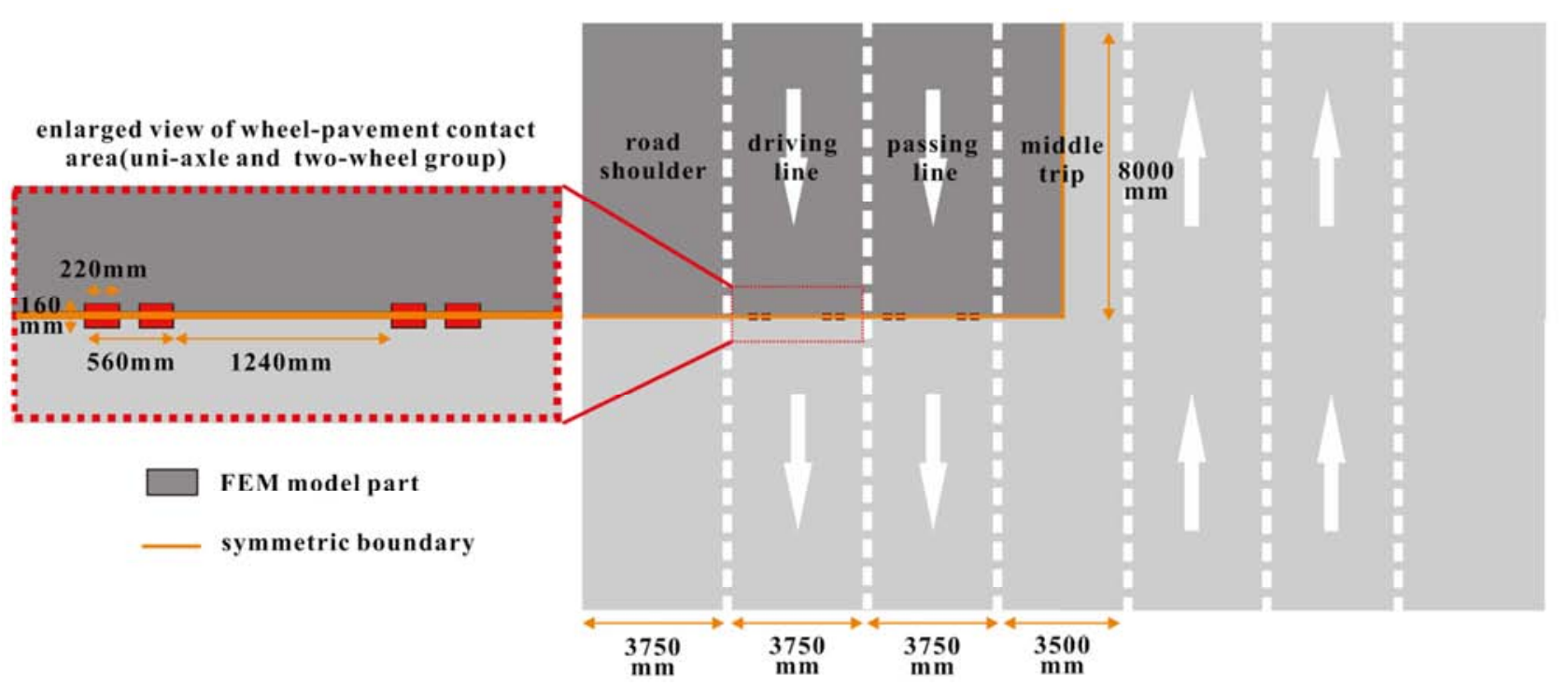

Figure 7. Top view of pavement schematic diagram of the FEM model and wheel-pavement contacting area.

The bottom boundary condition of the model is fixed constraint, and the four lateral planes are set as viscoelastic boundary to absorb stress wave. The mesh finite elements near the loading area are refined. The loading form of vehicle is uniaxial two-wheel group with $100 \mathrm{kN}$ axle load, which is a standard axle load used in expressway design in China as shown in Figure 7. The wheel-pavement contacting area is equivalent to rectangle with peak contacting pressure $700 \mathrm{kPa}$ in form of half-sinusoidal wave at $5 \mathrm{~Hz}$. Both driving lane and passing lane are presumed existing vehicles in order to simulate the highest loading the subgrade may bear. Implicit dynamic analysis method is adopted in calculation. Figure 8 is 
the contour picture of resilient modulus of subgrade soil under self-weight. It can be seen that resilient modulus values of different parts are various, which is resulted from spatial distribution difference of stress state. Figure 9 presents transverse and the vertical distribution of calculated $M_{\mathrm{r}}$ of unique nodal in subgrade. $M_{\mathrm{r}}$ rises with depth increase under self-weight effect and tends to constant beyond depth of $5 \mathrm{~m}$ (Figure 9 (a)). The $M_{\mathrm{r}}$ of roadbed is in the range of
$70 \mathrm{Mpa} \sim 100 \mathrm{Mpa}$, while it is in range of $60 \mathrm{Mpa} \sim 85 \mathrm{Mpa}$ at embankment part. Because EHSC with $K=0.96$ and $K=0.93$ have different N37AP1 model parameters, $M_{\mathrm{r}}$ changes abruptly in the bound between roadbed and embankment, which reflects compaction degree's influence on $M_{\mathrm{r}}$ in numerical study. As it shown in Figure 9 (b), $M_{\mathrm{r}}$ attenuates from the middle to the side of the subgrade, and the tendency becomes significant for larger subgrade depth.

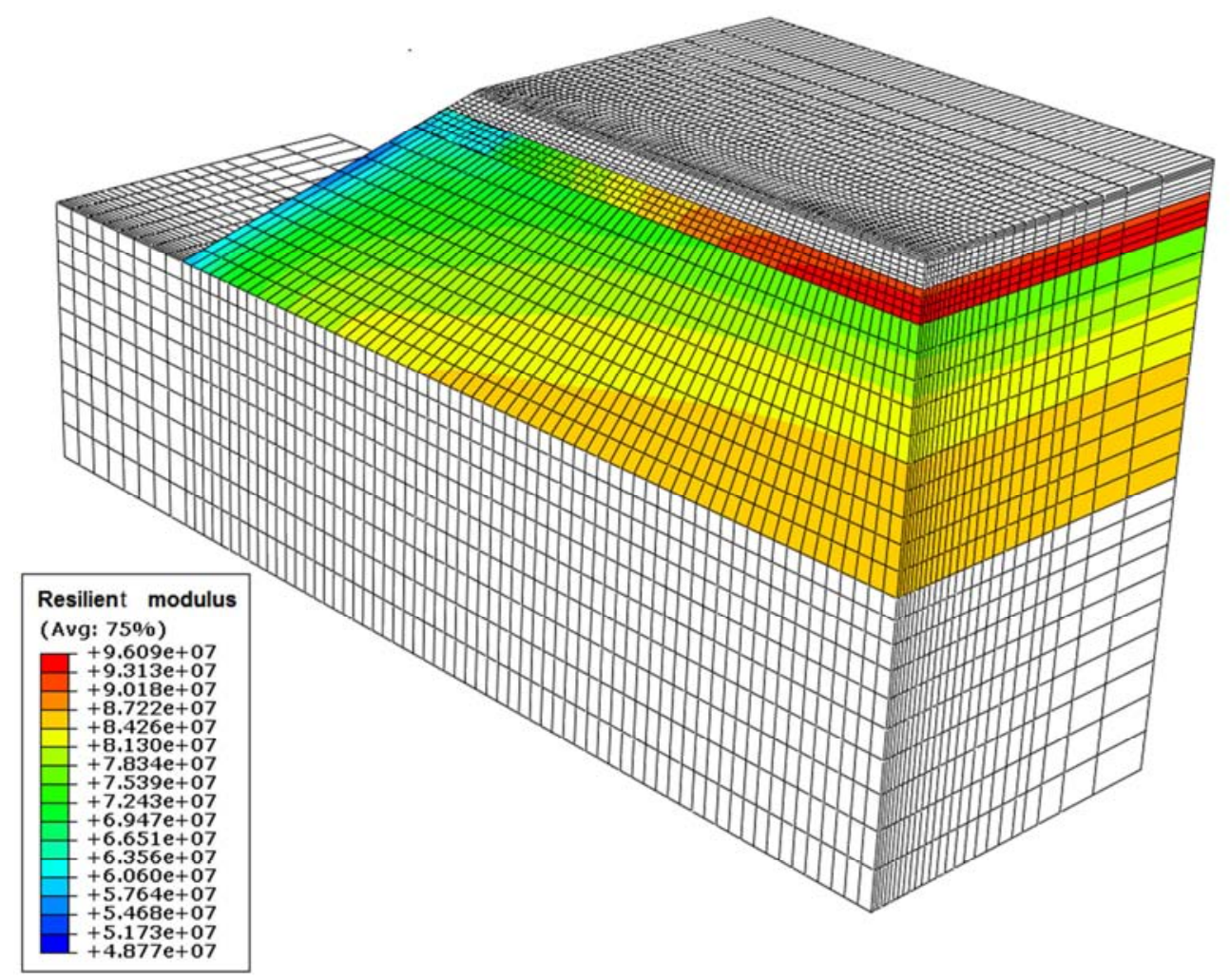

Figure 8. $M_{r}$ of subgrade with self-weight.

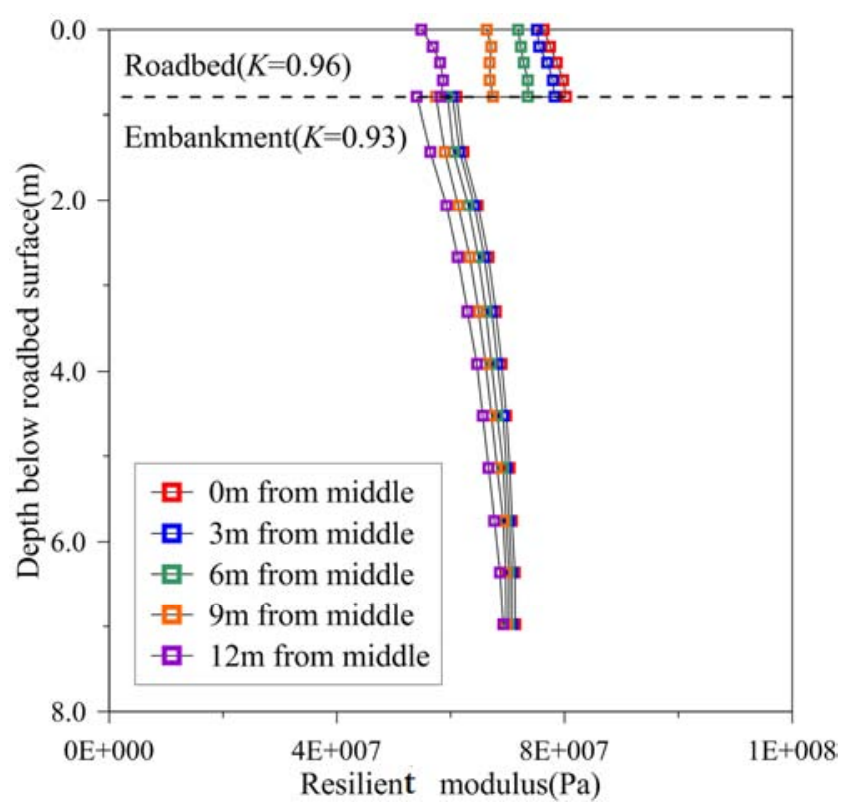

(a)

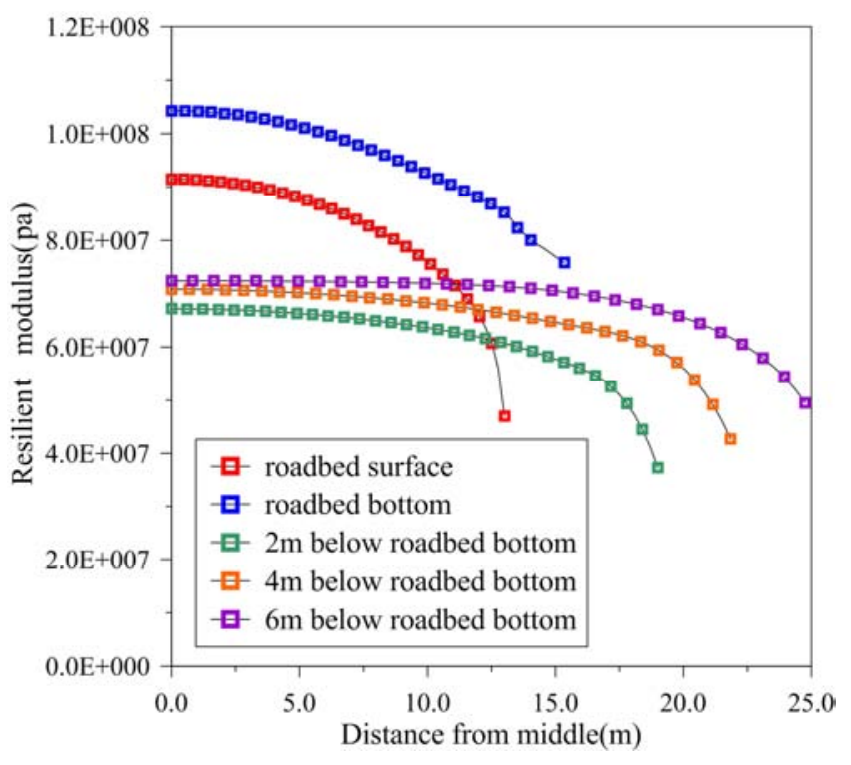

(b)

Figure 9. $M_{r}$ distribution curve of subgrade soil with self-weight: (a) vertical distribution; (b) transverse distribution. 
Figure 10 is the relative change rate contour picture of $M_{\mathrm{r}}$ caused by the change of stress states when vehicle loading is imposed on pavement surface. For the roadbed part underneath the wheel-pavement contacting area, $M_{\mathrm{r}}$ attenuates with a maximum amplitude $-1.3 \%$ because increase in deviator stress is dominated. In contrast, $M_{\mathrm{r}}$ of roadbed part underneath wheel clearance area increases with a maximum amplitude $2.0 \%$ because lateral compression effect is dominated. It seems that $M_{\mathrm{r}}$ at embankment part is less influenced by vehicle loading, totally showing negative value. Compared to self-weight condition, subgrade $M_{\mathrm{r}}$ will decrease when vehicle loading is considered. By using N37AP1 model into dynamic analysis, variation of resilient modulus in each element of subgrade caused by vehicle loading is realized.

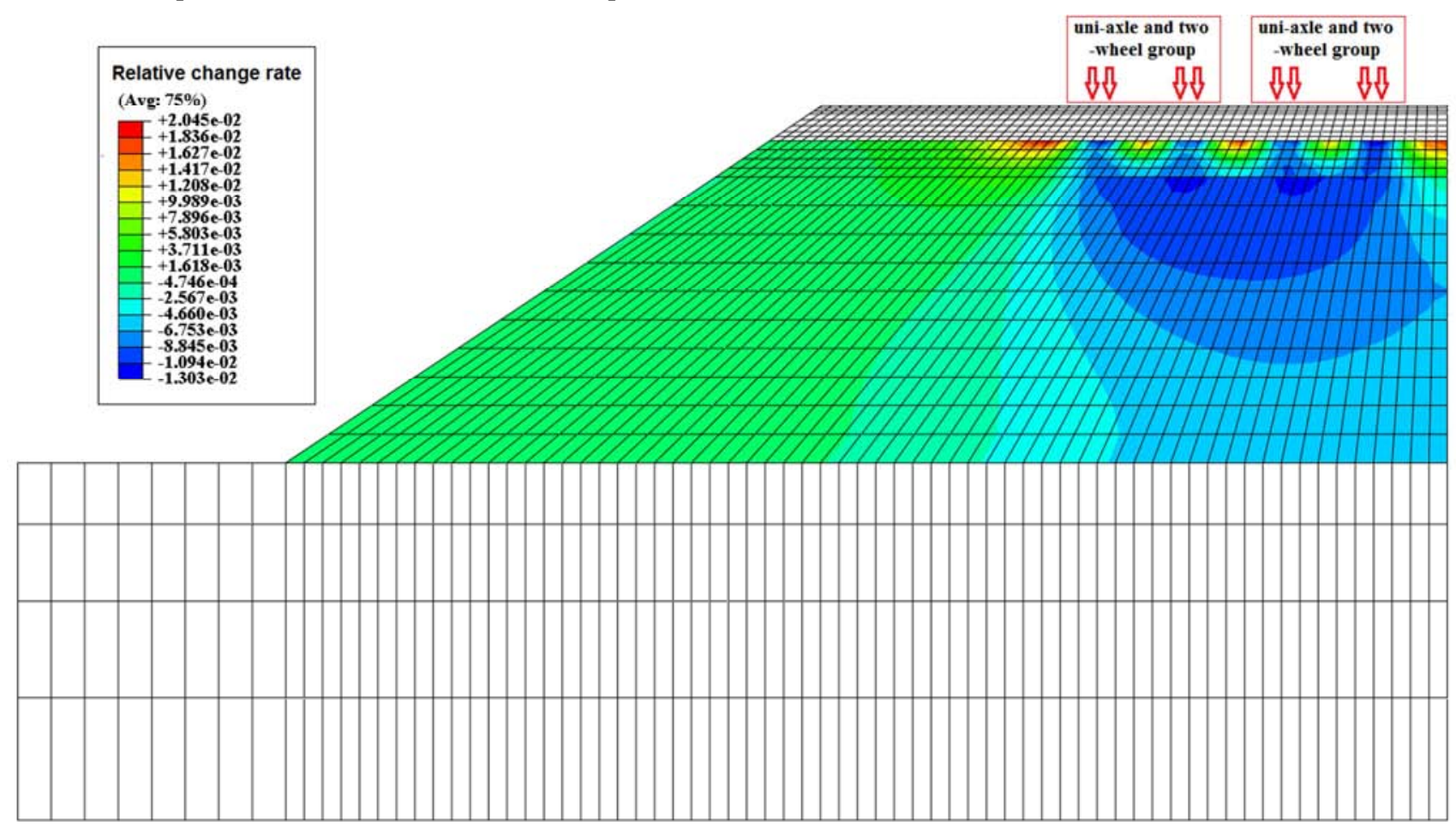

Figure 10. Contour picture of relative change rate of subgrade $M_{r}$ when vehicle loading is imposed.

\subsection{Comparison with Measured Values}

Figure 11 shows the comparison between calculated results and in-site measured results. Both calculated and measured results have similar variation trend with depth increases. It is indicated that when the axle load is $100 \mathrm{kN}$ or $120 \mathrm{kN}$, calculated stress and deformation are close to measured data. The error rises with increase in axle load. When axle load reaches $140 \mathrm{kN}$, calculated error of stress is large while calculated error of deformation keeps in $10 \%$. However, according to transportation volume investigation, ratio of $140 \mathrm{kN}$ axle load is only $4.3 \%$, and the percentage $100 \mathrm{kN} \sim 120 \mathrm{kN}$ axle load surpasses $85 \%$. Therefore, the calculated results used N37AP1 model is dependable in usual axle load range. In general, traditional linear elastic design method of subgrade is unreliable to some extent because of neglecting extra deformation resulting from subgrade $M_{\mathrm{r}}$ attenuation. In contrast, N37AP1 model is capable of stimulating $M_{\mathrm{r}}$ attenuation caused by vehicle loading so that corresponding calculation accuracy is enhanced. It provides important method and tool for subgrade design.

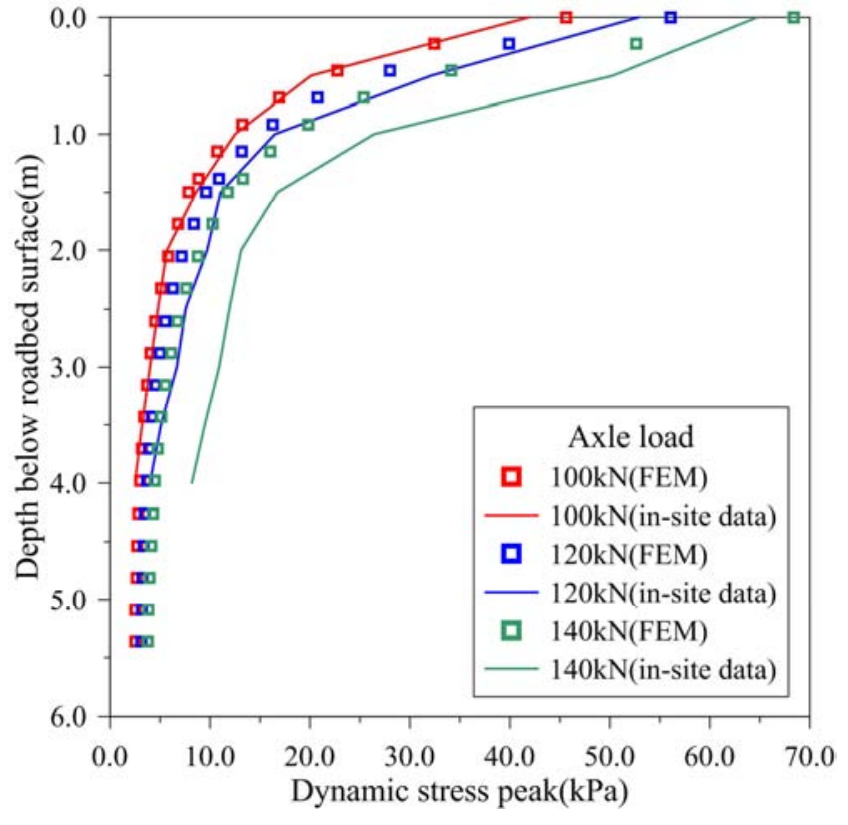

(a) Vertical dynamic stress peak 


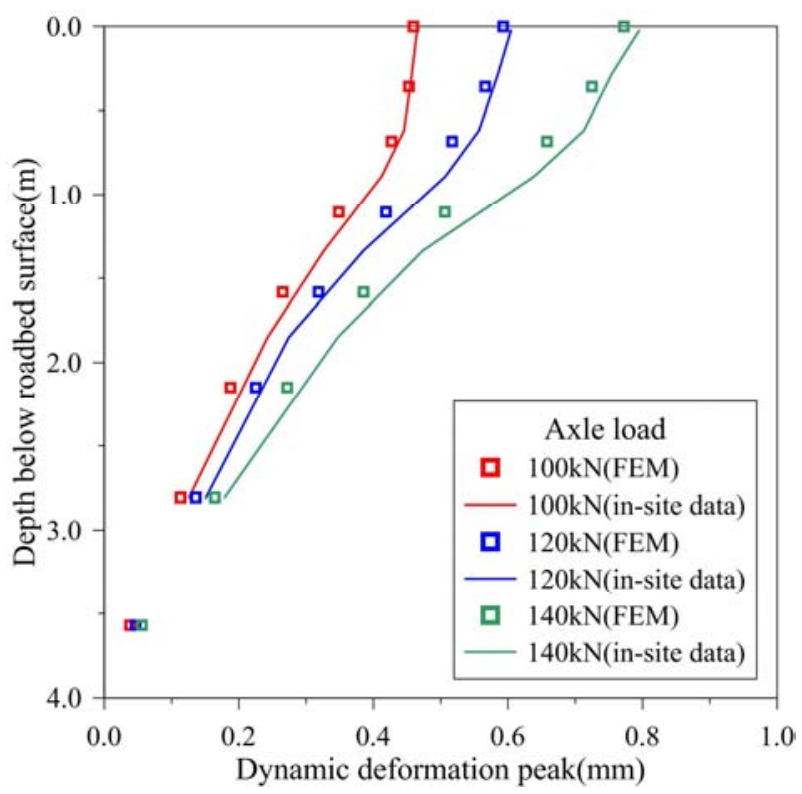

(b) Vertical dynamic deformation peak

Figure 11. Comparison between FEM calculated results and in-site measured results under different axle load.

\section{Conclusion}

For resilient behavior of Eastern Hunan silty clay, experimental studies were carried out in the current article. The major findings are summarized as follows:

According to the RCTT results, $M_{\mathrm{r}}$ of EHSC totally decreases with the rise of cyclic deviator stress and increases with the rise of bulk stress. Evidently, $M_{\mathrm{r}}$ is largely influenced by change of stress state. $M_{\mathrm{r}}$ also presents a positive correlation with compaction degree.

A improved prediction model (N37AP1 model) of $M_{\mathrm{r}}$ is proposed by adding $k_{4}$ parameter into N37A model to fine adjust the influence degree of octahedral shear stress on $M_{\mathrm{r}}$. N37AP1 model's prediction accuracy is obviously higher by comparison with N37A model and UZANAP1 model.

The verification work of N37AP1 on single element is put forward in condition of gradient loading. The result shows that the stress-strain curves when $k_{4}=0.1,1$ and 10 are very close to analytic solution, which indicates that derivation of Jacobian matrix and programming work are mainly correct.

When implementing N37AP1 model into FEM analysis on expressway structure, the calculated results can reflect the spatial difference of resilient modulus under self-weight effect as well as the influence of compaction degree. The evolution of resilient modulus under vehicle loading can also be exhibited.

The calculated results of stress and deformation used N37AP1 model is close to measured results in usual axle load range of $100 \mathrm{kN} \sim 120 \mathrm{kN}$. Relative to traditional prediction model and linear elastic design method, proposed N37AP1 model and related implementation work provide a more effective and accurate numerical method for studying subgrade's dynamic responses and subgrade design.

\section{Acknowledgements}

This work was supported by the Youth Talents Support Program of Hunan (grant number 2016RS3037); Fund of Post-doctoral Studies. The authors would like to thank all the members of Key Laboratory at Hunan Communication Research Institute, Changsha, China.

\section{References}

[1] Hossein N, Cyrille C, Maria IA, Pierre H, Farimah M. Unsaturated resilient behavior of a natural compacted sand. $\mathrm{J}$ Computers and Geotechnics, 2011; 38 (1): 491-503.

[2] Li ZY, Dong C, Zou JR. Research on experiment and prediction model of dynamic resilient modulus of laterite soil in Southern Hunan. J Rock and Soil Mechanics, 2015; 36 (7): 1840-1846. (in Chinese).

[3] Ni B, Hopkins TC, Sun L. Modeling the resilient modulus of soils. Proceedings of the 6th International Conference on the Bearing Capacity of Roads, Railways and Airfields. Lisbon; 2002, p. 1131-1142.

[4] Andrei D, Witczak MW, Schwartz CW. Harmonized resilient modulus test method for unbound pavement materials. 83rd Annual Meeting of Transportation Research Board; 2004.

[5] Fortunato E, Pinelo A, Fernandes MM. Characterization of the fouled ballast layer in the substructure of a $19^{\text {th }}$ century rail way track under renewal. J Soils Found, 2010; 50 (1): 55-62.

[6] Youngji J, Bin Y, Feng Z. Numerical simulation of sand subjected to cyclic load under undrained conventional Tri-axial test. J Soils Found, 2010; 50 (2): 177-194.

[7] Trinh VN, Tang AM, Cui YJ, Dupla JC, Canou J, Calon N, Lambert L, Robinet A, Schoen O. Mechanical characterization of the fouled ballast in an client railway track substructure by large-scale Tri-axial tests. J Soils Found, 2012; 52 (3): 511-523.

[8] Inam A, Ishikawa T, Miura S. Effect of principal stress axis rotation on cyclic plastic deformation characteristics of unsaturated base course material. J Soils Found, 2012; 52 (3): 465-480.

[9] Puppala AJ. Estimating stiffness of subgrade and unbound materials for pavement design, NCHRP Synthesis 382, Transportation Research Board, National Research Council, Washington, D. C; 2007.

[10] Uzan J. Characterization of granular material. Proceedings Transportation Research Record 1022 Washington; 1985, p. 52-59.

[11] Witczak MW, Uzan J. The universal airport pavement design system. Report I of V: Granular Material Characterization, Department of Civil Engineering, University of Maryland, College Park, Md; 1988.

[12] Chen SK, Ling JM, Luo ZG. Stress-dependent characteristics and prediction model of the resilient modulus of subgrade soils. J China Civil Engineering Journal, 2007; 40 (6): 95-99. (in Chinese).

[13] Allou F, Chazallon C, Hornych P. A numerical model for flexible pavements rut depth evolution with time. J Int J Numer Anal Methods Geomech, 2007; 31: 1-22. 
[14] Ling JM, Su HC, Xie HC. Library research on dynamic resilient modulus of subgrade soil. J Chinese Journal of Underground Space and Engineering, 2010; 6 (5): 919-925. (in Chinese).

[15] Andrei D, Witczak MW, Schwartz CW, Uzan J. Harmonized resilient modulus test method for unbound pavement materials. J Trans. Res. Rec. TRB, 2004: 29-37.

[16] Ministry of Communications of China. Specifications for design of highway subgrades. China Communications Press, Beijing; 2015. (in Chinese).

[17] Liu M. Analysis of the relationship among the statistical tests on linear regression model. J Statistics \& Information Forum, 2011; 26 (4): 21-24. (in Chinese).

[18] Dong C. Study on dynamic resilient modulus and critical dynamic stress of subgrade soil and performance analysis of subgrade and pavement (Ph. D. thesis). Changsha: Central South University; 2014. (in Chinese).

[19] Tommy C, Hopkins K, Tony L. Resilient modulus of Kentucky soils (Ph. D. thesis). Lexington: University of Kentucky; 2004.

[20] Taciroglu E. Constitutive modeling of the resilient response of granular solids (Ph. D. thesis). Illinois: University of Illinois at urbana-champaign urbana; 1998. 